\title{
Causes of erectile dysfunction in non-alcoholic fatty liver disease
}

\author{
D) Haluk Tarik Kani ${ }^{1}$, (1) Tarik Emre Sener ${ }^{2}$, (D) Umut Emre Aykut ${ }^{1}$, (10) Coskun Ozer Demirtas ${ }^{1}$, (D) Caglayan Keklikkiran ${ }^{1}$, \\ (D) Ilkay Ergenc ${ }^{1}$, (D) Abdullah Fatih Demircis ${ }^{3}$, (D) Haydar Kamil Cam², (D) Cigdem Celikel ${ }^{4}$, (D) Cem Akbal', (D) Deniz Duman ${ }^{1}$ \\ ${ }^{1}$ Department of Gastroenterology, Marmara University School of Medicine, Istanbul, Turkey; ${ }^{2}$ Department of Urology, Marmara University School of Medicine, \\ Istanbul, Turkey; ${ }^{3}$ Department of Internal Medicine, Marmara University School of Medicine, Istanbul, Turkey; ${ }^{4}$ Department of Pathology, Marmara University \\ School of Medicine, Istanbul, Turkey; ${ }^{5}$ Department of Urology, Acibadem Mehmet Ali Aydinlar University School of Medicine, Istanbul, Turkey
}

\begin{abstract}
Background and Aim: Erectile dysfunction (ED) is an important and commonly seen disorder in patients with non-alcoholic fatty liver disease (NAFLD). The objective of this study was to assess the rate of ED and its causes in a group of NAFLD patients.

Materials and Methods: The International Index of Erectile Function questionnaire (IIEF-5) was used to evaluate the presence, causes, and severity of ED. Participants with an IIEF-5 score of $<22$ who agreed to undergo a urological evaluation were referred to a urologist for further assessment.

Results: A total of 136 NAFLD patients were enrolled in the study. According to the IIEF-5, 68 (50.0\%) patients had ED. Multivariate analysis indicated that older age, obesity, and hypertension were associated with ED. Seventeen patients had multiple etiological factors for ED. Psychogenic ED was identified in 19 patients $(39.6 \%)$, vasculogenic ED in 35 patients $(72.9 \%)$, drug-related ED in 3 patients (6.3\%), and neurogenic ED in 6 patients $(12.5 \%)$.

Conclusion: ED is frequently seen in NAFLD patients, which may, at least in part, be due to common risk factors. Vasculogenic dysfunction is the most common single source of ED in NAFLD patients. Nonetheless, all potential etiologies should be carefully investigated, with special attention given to psychogenic factors, since they may be more frequent and relevant than expected.
\end{abstract}

Keywords: Erectile dysfunction; fatty liver; International Index of Erectile Function; non-alcoholic fatty liver disease.

\section{Introduction}

Non-alcoholic fatty liver disease (NAFLD) is characterized by fat deposition in hepatocytes ( $>5 \%$ of liver weight) without a history of significant alcohol consumption or concurrent chronic liver disease.

How to cite this article: Kani HT, Sener TE, Aykut UE, Demirtas CO, Keklikkiran $\mathrm{C}$, Ergenc I, et al. Causes of erectile dysfunction in non-alcoholic fatty liver disease. Hepatology Forum 2021; 2(2):60-63.

Received: April 12, 2021; Accepted: May 05, 2021; Available online: May 24, 2021

Corresponding author: Haluk Tarik Kani; Nigde Omer Halisdemir Universitesi, Egitim ve Arastirma Hastanesi, Gastroenteroloji Klinigi, Nigde, Turkey

Phone: +90 38823222 20; e-mail: drhtkani@gmail.com

(9) OPen access

c. This work is licensed under a Creative Commons Attribution-NonCommercial 4.0 International License.

(C) Copyright 2021 by Hepatology Forum - Available online at www.hepatologyforum.org
NAFLD includes a wide spectrum of disorders, from simple steatosis to non-alcoholic steatohepatitis, which can progress to cirrhosis and hepatocellular carcinoma. It is currently considered the most common chronic liver disease worldwide, especially in the Western world, with an approximate prevalence of $25 \%{ }^{[1]}$ NAFLD is considered a hepatic manifestation of metabolic syndrome, and is therefore associated with various disorders, such as renal dysfunction, cardiovascular disease, and sexual dysfunction. ${ }^{[2-4]}$ Alteration of sexual function, in particular, erectile dysfunction (ED), which is defined as the inability to achieve or maintain an erection sufficient for satisfactory sexual performance, is thought to be quite common among those with advanced liver disease. ${ }^{[5]}$ ED is an important disorder with a reported prevalence of $18.4 \%$ in the adult population. ${ }^{[6]}$ The primary underlying etiologies of ED in the general population are vasculogenic, neurogenic, and psychogenic in origin, but multiple etiologies may also be present in a single patient. ${ }^{[7]}$ ED and NAFLD have several common risk factors, including endothelial dysfunction, obesity, and diabetes mellitus. ${ }^{[8,9]}$ Moreover, sperm parameters in NAFLD patients have been found to be impaired compared with healthy males. ${ }^{[10]} \mathrm{A}$ few studies have noted that ED is an important and commonly observed co-disorder in NAFLD cases. ${ }^{[11,12]}$ However, knowledge of the ED etiology and its effects in patients with NAFLD remains limited. Evaluation of the underlying causes of ED is essential for appropriate management.

This multidisciplinary study was designed to assess the frequency and the distribution of major underlying etiologies of ED in patients with NAFLD.

\section{Materials and Methods}

The study was approved by the Marmara University Ethics Committee on December 2, 2016 (Study ID: 09.2016.593). The research was conducted in compliance with good clinical practice and the principles of the Declaration of Helsinki. All of the patients provided written, informed consent to participate.

Patients diagnosed with NAFLD between 2017 and 2018 at a single gastroenterology outpatient clinic were included in the study. Patients with cirrhosis were excluded. The diagnosis of NAFLD was established with evidence of hepatic steatosis observed using transabdominal ultrasonography in the absence of secondary causes of hepatic fat accumulation, such as significant alcohol consumption ( $\geq 30 \mathrm{~g}$ /day for men and $\geq 20 \mathrm{~g} /$ day for women), long-term use of steatogenic medication, monogenic hereditary disorders, viral or autoimmune hepatitis, hereditary hemochromatosis, or alpha 1-antitrypsin deficiency. ${ }^{[13-15]}$ 
Table 1. General characteristics of patients with and without erectile dysfunction according to International Index of Erectile Function questionnaire scores

\begin{tabular}{|c|c|c|c|}
\hline & All patients $(n=136)$ & With ED $(n=68)$ & Without ED $(n=68)$ \\
\hline Age (years) (mean $\pm S D)$ & $45.64 \pm 11.55$ & $48.65 \pm 11.83$ & $42.63 \pm 10.52$ \\
\hline \multicolumn{4}{|l|}{ Marital status (n, \%) } \\
\hline Married & $120(88.2)$ & $60(88.2)$ & $60(88.2)$ \\
\hline Divorced & $4(2.9)$ & $3(4.4)$ & $1(1.5)$ \\
\hline Single & $12(8.8)$ & $5(7.4)$ & $7(10.3)$ \\
\hline Height $(\mathrm{cm})($ mean $\pm S D)$ & $172.49 \pm 6.85$ & $171.17 \pm 6.59$ & $173.80 \pm 6.90$ \\
\hline Weight $(\mathrm{kg})($ mean \pm SD) & $89.12 \pm 15.70$ & $90.62 \pm 18.27$ & $87.62 \pm 12.58$ \\
\hline Body mass index $\left(\mathrm{kg} / \mathrm{m}^{2}\right)($ mean $\pm \mathrm{SD})$ & $30.00 \pm 5.27$ & $30.98 \pm 6.43$ & $29.02 \pm 3.55$ \\
\hline Waist circumference $(\mathrm{cm})($ mean $\pm S D)$ & $106.02 \pm 13.40$ & $107.38 \pm 13.06$ & $104.66 \pm 13.69$ \\
\hline Hip circumference $(\mathrm{cm})($ mean $\pm S D)$ & $106.27 \pm 9.37$ & $106.97 \pm 9.30$ & $115.57 \pm 9.46$ \\
\hline Fasting glucose $>100$ mg/dL (n, \%) & $72(52.9)$ & $34(50.0)$ & $38(55.9)$ \\
\hline Smoker (n, \%) & $97(71.3)$ & $46(67.6)$ & $51(75.0)$ \\
\hline Hypertension (n, \%) & $36(26.5)$ & $26(38.2)$ & $10(14.7)$ \\
\hline AST (IU/L) (median, range) & $29(9-286)$ & $31(9-117)$ & $28(12-286)$ \\
\hline ALT (IU/L) (median, range) & $44.5(13-297)$ & $44(14-231)$ & $45.5(13-297)$ \\
\hline Total cholesterol (mg/dL) (mean \pm SD) & $200.29 \pm 47.61$ & $197.91 \pm 44.44$ & $202.51 \pm 50.66$ \\
\hline HDL cholesterol (mg/dL) (mean \pm SD) & $43.40 \pm 9.36$ & $43.22 \pm 9.86$ & $43.56 \pm 8.95$ \\
\hline LDL cholesterol (mg/dL) (mean $\pm S D)$ & $122.04 \pm 39.24$ & $118.13 \pm 39.91$ & $125.90 \pm 38.52$ \\
\hline Triglycerides (mg/dL) (median, range) & $154(38-685)$ & $157.5(58-685)$ & $144(38-580)$ \\
\hline Metabolic syndrome (n, \%) & $52(38.2)$ & $30(44.1)$ & $22(32.4)$ \\
\hline
\end{tabular}

ALT: Alanine aminotransferase; AST: Aspartate aminotransferase; ED: Erectile dysfunction; HDL: High-density lipoprotein; IIEF: International Index of Erectile Function; LDL: Low-density lipoprotein; SD: Standard deviation.

A detailed medical history was recorded and a physical examination was performed for all of the study patients. Clinical and laboratory data and anthropometric measurements were collected retrospectively from the hospital's electronic database. Following a 12-hour fasting period, serum values of aspartate aminotransferase, alanine aminotransferase, platelet, albumin, total cholesterol, high-density lipoprotein, low-density lipoprotein cholesterol, triglycerides, plasma glucose concentration, and insulin level were measured as a part of routine follow-up tests for NAFLD patients and recorded. The body mass index (BMI) was calculated using the formula of the individual's weight in kilograms divided by height in meters squared. Waist circumference was measured at the midpoint between the lower costal border and the iliac crest at the end of normal expiration, and hip circumference was measured at the maximum circumference around the buttocks.

ED was assessed using the International Index of Erectile Function questionnaire (IIEF-5). ${ }^{[16,17]}$ All of the participants completed the IIEF5 questionnaire under the supervision of a physician. The total score of the questionnaire ranges from 5 to 25 , and scores $>21$ were classified as the absence of ED. Participants with a score of $<22$ and who agreed to undergo a urological evaluation were referred to see a urologist (TES). A urogenital physical examination was performed and a urological medical history was recorded. The etiology of ED was evaluated and the pathophysiology was classified as vasculogenic, neurogenic, anatomical/structural, drug-induced, or mixed ED. ${ }^{[18]}$

Normally distributed data were expressed as the mean $\pm \mathrm{SD}$, and non-normally distributed data were presented as the median value. Variables were compared using an independent t-test or the Mann-Whitney $\mathrm{U}$ test according to the normality of distribution. A multivariate logistic
Table 2. Estimated coefficients determined using multivariable logistic regression with descriptors and clinical demographic data

\begin{tabular}{llll}
\hline & Coefficient & OR $(95 \% \mathrm{Cl})$ & $\mathbf{p}$ \\
\hline Age & -0.048 & 0.953 & $0.003^{*}$ \\
Obesity & 0.779 & 2.179 & $0.026^{*}$ \\
Hypertension & 1.278 & 3.590 & $0.003^{*}$ \\
\hline
\end{tabular}

Cl: Confidence interval; OR: Odds ratio; *: $\mathrm{p}<0.05$ was accepted as significant.

regression model was used to assess the factors that contributed to ED. A $p$ value of $<0.05$ was considered statistically significant.

\section{Results}

A total of 136 patients with NAFLD were enrolled in this study. The mean age was $45.64 \pm 1.55$ years. The gender orientation of all of the study participants was heterosexual. According to the IIEF-5, 68 $(50.0 \%)$ patients had ED. In the group, $120(88.2 \%)$ patients were married, $14(10.3 \%)$ patients had a BMI between $18.5 \mathrm{~kg} / \mathrm{m}^{2}$ and 24.9 $\mathrm{kg} / \mathrm{m}^{2}, 36(26.5 \%)$ had a diagnosis of hypertension, $97(71.3 \%)$ were smokers, and $72(52.9 \%)$ had a fasting glucose level of $\geq 100 \mathrm{mg} / \mathrm{dL}$ or a prior diagnosis of diabetes mellitus (Table 1).

Multivariate analysis revealed that older age, obesity, and hypertension were associated with ED in NAFLD patients $(\mathrm{p}=0.003,0.026$, and 0.003 , respectively) (Table 2). 
Table 3. Distribution of mixed ED etiologies in NAFLD patients

\begin{tabular}{lllll}
\hline & Vasculogenic ED & Psychogenic ED & Neurogenic ED & Drug-related ED \\
\hline Vasculogenic ED $(n=35)$ & & 8 & 5 & 3 \\
Psychogenic ED $(n=16)$ & 8 & & 1 & 0 \\
Neurogenic ED $(n=6)$ & 5 & 1 & 0 & 0 \\
Drug-related ED $(n=3)$ & 3 & 0 & 0 & \\
\hline
\end{tabular}

ED: Erectile dysfunction; NAFLD: Non-alcoholic fatty liver disease.

Forty-eight patients agreed to a urological examination, and ED was not confirmed in $5(10.4 \%)$ of those patients. Seventeen patients had multiple etiologies for ED. Psychogenic ED was identified in 19 patients $(39.6 \%)$, vasculogenic ED in $35(72.9 \%)$ patients, drug-related ED in $3(6.3 \%)$ patients, and neurogenic ED in $6(12.5 \%)$ patients (Table 3$)$. Twenty-nine $(60.4 \%)$ patients reported premature ejaculation and $4(2.9 \%)$ patients described a loss of sexual desire. Medical treatment for ED was prescribed for $36(75.0 \%)$ patients.

\section{Discussion}

The findings of the present study are a valuable contribution to the currently limited literature regarding the relationship between NAFLD and ED. The IIEF-5 questionnaire results indicated that there was an ED frequency of $50 \%$ among consecutive patients with NAFLD seen at a single tertiary center. As in the general population, older age, obesity, and hypertension were found to be associated with ED in our NAFLD cohort. Vasculogenic disorder was the most common etiology of ED in the group, which is similar to results for the general population. To the best of our knowledge, this is the first study to evaluate the underlying etiologies of ED in patients with NAFLD.

In an earlier study conducted by our team, the frequency of ED was $67.5 \%$ in patients with biopsy-proven NAFLD ${ }^{[12]}$ In the current research, ultrasound was used to screen for NAFLD and returned a lower rate of ED. This was likely due to the severity or stage of disease; in the previous cohort, there was a prominent nonalcoholic steatohepatitis (NASH) dominance, which is a more advanced stage of hepatic steatosis with inflammation. The lack of liver biopsy results precluded the calculation of the prevalence of NASH rates in the present study, which may be relevant to the interpretation of the findings. The rate of ED was $45.8 \%$ in a hospital-based study of 192 consecutive male patients that used radiological methods, rather than liver biopsy, to diagnose NAFLD. ${ }^{[1]}$ That is to say, the modality used to detect NAFLD may have contributed to the differences between studies. The frequency of ED can be projected to be somewhere between $45 \%$ and $67 \%$ among patients with NAFLD.

The reported ED rates in NAFLD patients are far higher than that of the general population, which has been reported to be $18.4 \%$ among males over 20 years of age in the United States. ${ }^{[6]}$ This may be related to common metabolic risk factors for NAFLD and ED, such as obesity and diabetes mellitus. ${ }^{[19-21]}$ Given the significant proportion of patients with NAFLD suffering from ED, efforts to understand the causes and to find novel therapeutic approaches could have a substantial impact on the quality of life of this patient group.

Hasanain et al. ${ }^{[11]}$ found that older age, obesity, and hypertension were significantly more frequent in patients with NAFLD and ED, but multivariate analysis yielded only age as a variable associated with ED. We found that obesity and hypertension were also associated with ED in patients with NAFLD, in addition to age. These factors are associated both with NAFLD and ED; the combination and potential interaction merits clarification in future studies.

To our knowledge, this is the first study to examine the underlying etiologies of ED in NAFLD patients. We found that $39.5 \%$ of the NAFLD patients had multiple etiologies of ED. The most common etiology in our study group was a vasculogenic disorder, which was also probably linked to obesity, diabetes, or atherosclerosis. Notably, psychogenic ED was found in $39.6 \%$ of the NAFLD cases; thus, psychological disorders must also be evaluated carefully in NAFLD patients with concomitant ED.

Limitations of this research include the fact that it was a single-center study conducted with a small number of patients. Also, since this was a cross-sectional study, only the causes of ED in consecutive NAFLD patients who were diagnosed with ED were analyzed; the response to ED treatment was not evaluated. Future studies to examine the longterm results of ED treatment in NAFLD patients and the potential influence on the progress of NAFLD are warranted. In addition, a detailed endocrinological evaluation would add value to the findings of the present study.

In conclusion, ED is common in patients with NAFLD, and may be related to common risk factors. Vasculogenic ED is the most common single cause of ED in patients with NAFLD; however, all possible etiologies should be carefully assessed, and special attention should be given to psychogenic ED, since it has been detected in a non-negligible percentage of patients with NAFLD.

Ethics Committee Approval: The Marmara University Clinical Research Ethics Committee granted approval for this study (date: 02.12.2016, number: 09.2016.593).

Peer-review: Externally peer-reviewed.

Author Contributions: Concept - HKC, DD; Design - HKC, DD, HTK, TES; Supervision - HKC, DD; Fundings - HKC, DD, HTK, TES; Materials - HTK, TES, UEA, COD, CK, IE, AFD; Data Collection and/or Processing - HTK, TES, UEA, COD, CK, IE, AFD, CC, CA, HKC, DD; Analysis and/or Interpretation - HTK, TES, UEA, COD, CK, IE, AFD, CC, CA, HKC, DD; Literature Search - HTK, TES, UEA, COD, CK, IE, AFD, CC, CA, HKC, DD; Writing - HTK, TES, UEA, COD, CK, IE, AFD, CC, CA, HKC, DD; Critical Reviews - HTK, TES, UEA, COD, CK, IE, AFD, CC, CA, HKC, DD.

Conflict of Interest: The authors have no conflict of interest to declare.

Financial Disclosure: The authors declared that this study has received no financial support.

\section{References}

1. Younossi Z, Anstee QM, Marietti M, Hardy T, Henry L, Eslam M, et al. Global burden of NAFLD and NASH: trends, predictions, risk factors and prevention. Nat Rev Gastroenterol Hepatol 2018;15(1):11-20. [CrossRef] 
2. Sun DQ, Ye FZ, Kani HT, Yang JR, Zheng KI, Zhang HY, et al. Higher liver stiffness scores are associated with early kidney dysfunction in patients with histologically proven non-cirrhotic NAFLD. Diabetes Metab 2020;46(4):288-295. [CrossRef]

3. Hawksworth DJ, Burnett AL. Nonalcoholic fatty liver disease, male sexual dysfunction, and infertility: common links, common problems. Sex Med Rev 2020;8(2):274-285. [CrossRef]

4. Caussy C, Aubin A, Loomba R. The relationship between type 2 diabetes, NAFLD, and cardiovascular risk. Curr Diab Rep 2021;21(5):15.

5. Durazzo M, Premoli A, Di Bisceglie C, Bo S, Ghigo E, Manieri C. Male sexual disturbances in liver diseases: what do we know? J Endocrinol Invest 2010;33(7):501-505. [CrossRef]

6. Selvin E, Burnett AL, Platz EA. Prevalence and risk factors for erectile dysfunction in the US. Am J Med 2007;120(2):151-157. [CrossRef]

7. Celik O, Ipekci T, Akarken I, Ekin G, Koksal T. To evaluate the etiology of erectile dysfunction: What should we know currently? Arch Ital Urol Androl 2014;86(3):197-201. [CrossRef]

8. Yilmaz Y, Eren F. Hepatic fibrosis - and not steatosis - is the main determinant of arterial stiffness in non-alcoholic fatty liver disease. Atherosclerosis 2019;290:222-223. [CrossRef]

9. Montorsi F, Adaikan G, Becher E, Giuliano F, Khoury S, Lue TF, et al. Summary of the recommendations on sexual dysfunctions in men. J Sex Med 2010;7(11):3572-3588. [CrossRef]

10. Li Y, Liu L, Wang B, Chen D, Wang J. Nonalcoholic fatty liver disease and alteration in semen quality and reproductive hormones. Eur J Gastroenterol Hepatol 2015;27(9):1069-1073. [CrossRef]

11. Hasanain AFA, Mahdy RE, Mahran AMA, Safwat ASM, Mohamed AO, Abdel-Aal SM. Erectile dysfunction in patients with nonalcoholic fatty liver disease. Arab J Gastroenterol 2017;18(1):21-24. [CrossRef]

12. Duman DG, Biçakci E, Çelikel ÇA, Akbal C. Nonalcoholic Fatty Liver Disease is Associated with Erectile Dysfunction: A Prospective Pilot Study. J Sex Med 2016;13(3):383-388. [CrossRef]
13. Ratziu V, Bellentani S, Cortez-Pinto H, Day C, Marchesini G. A position statement on NAFLD/NASH based on the EASL 2009 special conference. J Hepatol 2010;53(2):372-384. [CrossRef]

14. European Association for the Study of the Liver (EASL); European Association for the Study of Diabetes (EASD); European Association for the Study of Obesity (EASO). EASL-EASD-EASO Clinical Practice Guidelines for the management of non-alcoholic fatty liver disease. J Hepatol 2016;64(6):1388-1402. [CrossRef]

15. Chalasani N, Younossi Z, Lavine JE, Charlton M, Cusi K, Rinella M, et al. The diagnosis and management of nonalcoholic fatty liver disease: Practice guidance from the American Association for the Study of Liver Diseases. Hepatology 2018;67(1):328-357. [CrossRef]

16. Turunc T, Deveci S, Guvel S, Peskircioglu L. The assessment of Turkish validation with 5 question version of International Index of Erectile Function (IIEF-5). Turk Uroloji Dergisi 2007;33(1):45-49.

17. Rosen RC, Cappelleri JC, Smith MD, Lipsky J, Peña BM. Development and evaluation of an abridged, 5-item version of the International Index of Erectile Function (IIEF-5) as a diagnostic tool for erectile dysfunction. Int J Impot Res 1999;11(6):319-326. [CrossRef]

18. Salonia A, Bettochi C, Carvalho J, Corona G, Jones TH, Kadioglu A, et al. EAU Guidelines on Sexual and Reproductive Health. Arnhem: The Netherlands European Association of Urology Guidelines Office; 2020.

19. Saigal CS, Wessells H, Pace J, Schonlau M, Wilt TJ; Urologic Diseases in America Project. Predictors and prevalence of erectile dysfunction in a racially diverse population. Arch Intern Med 2006;166(2):207-212

20. Tada T, Toyoda H, Sone Y, Yasuda S, Miyake N, Kumada T, et al. Type 2 diabetes mellitus: A risk factor for progression of liver fibrosis in middleaged patients with non-alcoholic fatty liver disease. J Gastroenterol Hepatol 2019;34(11):2011-2018. [CrossRef]

21. Kim Y, Chang Y, Cho YK, Ahn J, Shin H, Ryu S. Obesity and Weight Gain Are Associated With Progression of Fibrosis in Patients With Nonalcoholic Fatty Liver Disease. Clin Gastroenterol Hepatol 2019;17(3):543-550.e2. 